\title{
Thermally Stable and Antimicrobial Active Poly(Catechin) Obtained by Reaction with a Cross-Linking Agent
}

\author{
Malgorzata Latos-Brozio ${ }^{1}$ (D), Anna Masek ${ }^{1, *(D)}$ and Małgorzata Piotrowska ${ }^{2}$ (D) \\ 1 Faculty of Chemistry, Institute of Polymer and Dye Technology, Lodz University of Technology, \\ Stefanowskiego 12/16, 90-924 Lodz, Poland; malgorzata.latos@p.lodz.pl \\ 2 Faculty of Biotechnology and Food Sciences, Institute of Fermentation Technology and Microbiology, \\ Lodz University of Technology, Wólczańska 71/173, 90-924 Lodz, Poland; malgorzata.piotrowska@p.lodz.pl \\ * Correspondence: anna.masek@p.lodz.pl; Tel.: +48-42-631-32-93-X
}

Citation: Latos-Brozio, M.; Masek, A Piotrowska, M. Thermally Stable and Antimicrobial Active Poly(Catechin) Obtained by Reaction with a Cross-Linking Agent. Biomolecules 2021, 11, 50. https://doi.org/ 10.3390/biom 11010050

Received: 23 November 2020 Accepted: 28 December 2020 Published: 31 December 2020

Publisher's Note: MDPI stays neutral with regard to jurisdictional clai$\mathrm{ms}$ in published maps and institutional affiliations.

Copyright: (C) 2020 by the authors. Licensee MDPI, Basel, Switzerland. This article is an open access article distributed under the terms and conditions of the Creative Commons Attribution (CC BY) license (https:// creativecommons.org/licenses/by/ $4.0 /)$.

\begin{abstract}
Catechin is a flavonoid with valuable antioxidant and antimicrobial properties, found in significant amounts in green tea leaves. Polymeric forms of catechin have been obtained by enzymatic reaction, photopolymerization, and polycondensation in designed processes. However, so far, poly(catechin) has not been received in the cross-linking reaction. Reactions with the crosslinking compound allowed for the preparation of antibacterial and antioxidant materials based on quercetin and rutin. The aim of the research was to obtain, for the first time, poly(catechin) by reaction with glycerol diglycide ether cross-linking compound. The polymeric form of (+)-catechin was confirmed using FTIR and UV-Vis spectroscopy. In addition, thermal analysis (TG and DSC) of the polymeric catechin was performed. The antioxidant and antibacterial activity of poly (flavonoid) was also analyzed. Poly(catechin) was characterized by greater resistance to oxidation, better thermal stability and the ability to reduce transition metal ions than (+)-catechin. In addition, the polymeric catechin had an antimicrobial activity against Staphylococcus aureus stronger than the monomer, and an antifungal activity against Aspergillus niger comparable to that of (+)-catechin. The material made on the basis of $(+)$-catechin can potentially be used as a pro-ecological stabilizer and functional additive, e.g., for polymeric materials as well as dressing materials in medicine.
\end{abstract}

Keywords: (+)-catechin; polymerization; cross-linking compound; antioxidant properties; thermal analysis

\section{Introduction}

Catechin (flavan-3-ol) and its derivatives are polyphenolic compounds, found in significant amounts in green tea, cocoa, red wines, and chocolate. This plant flavonoid is known for its strong antioxidant properties and has been proposed in the literature as an anti-aging substance. Moreover, catechins also show antibacterial and antifungal activity [1-6].

The valuable properties of compounds from the group of flavonoids closely depend on their chemical structure. Flavonoids are based on the flavan structure, thus the number, positions, and types of substitutions influence radical scavenging and chelating activity, as well as their pharmacological activities such as antiviral/antibacterial, cytotoxic, cardioprotective and anti-inflammatory activities. The relationship of the structure and properties of low molecular weight flavonoids is analyzed in detail. The influence of individual structural elements of flavonoids on the efficiency of scavenging free radicals and pharmacological action is described comprehensively. However, correlations between the structure of polymeric forms and their activity are poorly researched [7-11].

In plant materials, catechins occur in many oligomeric forms, primarily condensed tannins (also known as proanthocyanidins) [12]. Literature data show that the polymerized structures of flavonoids may be characterized by stronger antioxidant properties, better 
antimicrobial activity and higher thermal stability [13-15]. It has been shown that increasing the degree of polymerization of oligomeric or polymeric flavan-3-ols increases their radical reduction efficiency. Significant free radical scavenging properties by the polymeric structures are the result of extensive conjugation between 3-OH and B-ring catechol groups, together with abundant $\beta 4 \rightarrow 8$ linkages [16]. Moreover, studies have shown that dimeric flavan-3-ols play an important, protective role in the human diet [17].

As far as this, the polymeric catechin has been obtained by enzymatic polymerization [18-20], photopolymerization [21], $\mathrm{HCl}$ acid catalyzed polymerization [22], and polycondensation of catechins with aldehydes in the presence of acid catalyst [23-25].

Another method to acquire poly(flavonoids) is a polymerization reaction with a crosslinking compound. Sahiner proposed a method of obtaining polymeric forms of flavonoids, such as quercetin and its glycoside - rutin, consisting in polymerization with a cross-linking compound in the form of glycerol diglycide ether (GDE), using L- $\alpha$ lecithin as a surface-active agent, in a cyclohexane environment in the case of obtaining poly(quercetin) or in the gasoline environment when obtaining poly(rutin). Polyfunctional crosslinker glycerol diglycidyl ether (GDE) is a biocompatible material and can be used to connect monomeric flavonoids into a particle form. The epoxy groups in GDE readily react with the phenolic $\mathrm{OH}$ groups in the flavonoids to form polymeric structures [26,27].

The aim of the study is to obtain poly(catechin) by reaction with an epoxy cross-linking agent. Based on the literature data review, it was found that this polymeric, cross-linked catechin compound has not yet been described. The crosslinking reaction was used only to prepare poly(quercetin) and poly(rutin) [26,27]. The molecule of quercetin and rutin, flavonoids from the flavonols group, contains, like most flavonoids, a carbon skeleton with a ketone group in the 4-position, while catechins from the flavan-3-ol group of flavonoids do not contain a keto group in the carbon skeleton, and so they are fundamentally different in chemical structure from quercetin and rutin. Besides the polymerization reaction of catechin with the crosslinker, this manuscript also describes the properties of the obtained poly(catechin), such as antioxidant activity, thermal stability, and antibacterial properties

\section{Materials and Methods}

\subsection{Preparation of Poly(Catechin) in the Cross-Linking Reaction}

Catechin ((+)-catechin hydrat $\geq 98 \%$ HPLC, MW: 290,27 g/mol, Sigma Aldrich, product of China) polymerization was performed according to the method proposed by Sahiner $[26,27]$ with minor modifications. First, a solution of $(+)$-catechin was prepared by dissolving $1 \mathrm{~g}$ of (+)-catechin in $10 \mathrm{~mL}$ of $1 \mathrm{M} \mathrm{NaOH}$ (ChemPur, Piekary Slaskie, Poland). Then, $4 \mathrm{~mL}$ of this solution was added to $150 \mathrm{~mL}$ of a $0.1 \mathrm{M}$ solution of L- $\alpha$-lecithin (from soybean, $\geq 99 \%$, MilliporeSigma, Darmstadt, Germany) in cyclohexane $(96 \%$, pure. P.A., ChemPur, Poland). The solution was stirred for $2 \mathrm{~h}$ at $1000 \mathrm{rpm}$ at $20^{\circ} \mathrm{C}$, after which time glycerol diglycidyl ether (GDE, technical grade, Sigma-Aldrich, Steinheim, Germany) was added in an amount of $100 \mathrm{~mol} \%$ with respect to the catechin used. After $2 \mathrm{~h}$ of stirring (1000 rpm), the obtained poly(catechin) was washed twice with cyclohexane by centrifugation (6000 rpm, room temperature). The poly(catechin) was dried at $35^{\circ} \mathrm{C}$ for $72 \mathrm{~h}$.

\subsection{Infrared (FTIR) and UV-Vis Spectroscopy}

A Nicolet 670 FTIR spectrophotometer (Thermo Fisher Scientific, Waltham, MA, USA) was utilized to analyze the poly(catechin) structure. Samples of (+)-catechin and polymeric form of $(+)$-catechin were placed at the output of infrared beams. Oscillating spectra were obtained as the result of the test. The analysis of oscillating spectra allows determination of the functional groups with which the radiation interacted.

The spectra of (+)-catechin and poly(catechin) powders at wavelengths of 190-1100nm were recorded using a UV-Vis spectrophotometer (Evolution 220, Thermo Fisher Scientific, Waltham, MA, USA). 


\subsection{Scanning Electron Microscopy (SEM)}

Based on the images obtained from the scanning electron microscope (SEM) LEO 1530 (Carl Zeiss AG, Oberchoken, Germany), the morphology of (+)-catechin and poly(catechin) powders was evaluated. Magnification was 10,000, 25,000 and 50,000×.

\subsection{Thermal Analysis of (+)-Catechin and Poly(Catechin)}

Thermogravimetric (TG) analysis: thermal stability of (+)-catechin and poly(catechin) was performed utilizing a Mettler Toledo Thermobalance (TA Instruments, Greifensee, Zürich, Switzerland). Samples of $10 \mathrm{mg}$ were placed in alumina crucibles and heated from $25^{\circ} \mathrm{C}$ to $800^{\circ} \mathrm{C}$ under argon flow $(50 \mathrm{~mL} / \mathrm{min})$ at heating rate of $5{ }^{\circ} \mathrm{C} / \mathrm{min}$.

Differential scanning calorimetry (DSC): temperature ranges of (+)-catechin and poly(catechin) phase changes were determined using a Mettler Toledo DSC analyser (TA 2920; TA Instruments, Greifensee, Zürich, Switzerland). The samples of 5-6 mg (placed in $100 \mu \mathrm{L}$ aluminium pans) were heated from -80 to $400{ }^{\circ} \mathrm{C}$ at a rate of $10^{\circ} \mathrm{C} / \mathrm{min}$ in air.

For thermal analysis (DSC and TGA) the values specified by the apparatus manufacturer were given as the measurement uncertainty.

\subsection{Antioxidant Tests}

ABTS and DPPHaAnalysis: The antioxidant capacity of catechin and poly(catechin) was determined by ABTS and DPPH tests. These methods are based on reduction of free radicals ABTS (2,2'-azino-bis(3-ethylbenzothiazoline-6-sulphonic acid)) and DPPH (2,2-diphenyl-1-picrylhydrazyl).

The $\mathrm{ABTS}^{\bullet+}$ radical was obtained by the mixing of a $6 \mathrm{mM}$ ABTS (assay $\geq 98 \%$, Sigma Aldrich, Saint Louis, MO, USA) solution in distilled water with potassium persulfate (2.45 mM; 99.99\%, Sigma Aldrich, Saint Louis, MO, USA) in the dark at $20{ }^{\circ} \mathrm{C}$ for $15 \mathrm{~h}$ before use. The absorbance of the $\mathrm{ABTS}^{\bullet+}$ solution was adjusted with EtOH (pure P.A., $96 \%, \mathrm{POCH}$, Gliwice, Poland) to $0.70 \pm 0.03$ at $734 \mathrm{~nm}$ at room temperature. Then, the ABTS $^{\bullet+}$ solution $(1.0 \mathrm{~mL})$ was mixed with $0.95 \mathrm{~mL}$ of ethanol and $50 \mu \mathrm{L}$ of catechin or poly(catechin) $(0.1 \mathrm{mg} / \mathrm{mL}$ in distilled water). The absorbance was measured at $734 \mathrm{~nm}$ after 2 min utilizing a UV-spectrophotometer (Evolution 220, Thermo Fisher Scientific, Waltham, MA, USA).

The ethanolic solution of DPPH $(2.0 \mathrm{~mL}, 40 \mathrm{mg} / \mathrm{mL} ;<=100 \%$, Sigma Aldrich, Germany) was added to $0.5 \mathrm{~mL}$ of distilled water containing $1 \mathrm{mg} / \mathrm{mL}$ catechin or poly(catechin)DPPH solution, which has a purple colour with a maximum absorbance at $517 \mathrm{~nm}$. Distilled water was used as a blank in ABTS and DPPH methods.

Level of inhibition (\%) of free radicals ABTS and DPPH was calculated according to the equation:

$$
\text { Inhibition }(\%)=\left[\left(\left(\mathrm{A}_{0}-\mathrm{A}_{1}\right) / \mathrm{A}_{0}\right) \times 100\right.
$$

where $A_{0}$ is the absorbance of the reference sample without antioxidants, and $A_{1}$ is the absorbance in the presence of catechin or poly(catechin) [28].

The inhibition level (\%) of absorbance was calculated using the standard curve prepared with Trolox (\% inhibition level - $\mu \mathrm{M}$ Trolox). The effect of catechin and poly(catechin) on scavenging ABTS and DPPH is referred to as the Trolox equivalent antioxidant capacity (TEAC).

The ABTS and DPPH tests were performed on three control samples and the average results were shown in the manuscript. Calculations were made for the means and standard deviations of three independent samples $(n=3)$. The measurement uncertainty was given as standard deviation.

FRAP and CUPRAC Analysis: The FRAP (ferric reducing antioxidant power) and CUPRAC (cupric reducing antioxidant capacity) tests were used to assess the ability of catechin or poly(catechin) to reduce transition metal ions. The FRAP method is based on the reduction of the ferric ion $\left(\mathrm{Fe}^{3+} \rightarrow \mathrm{Fe}^{2+}\right)$ under acidic conditions. The CUPRAC test is analogous to the FRAP assay and consists of the reduction of $\mathrm{Cu}^{2+}$ to $\mathrm{Cu}^{1+}$. 
The FRAP solution was freshly prepared by mixing $25 \mathrm{~mL}$ of acetate buffer solution (0.3 M, pH 3.6; Chempur, Piekary Slaskie, Poland), $2.25 \mathrm{~mL}$ of $10 \mathrm{mM}$ TPTZ (2,4,6-Tris (2-pyridyl)-s-triazine; $\geq 99.0 \%$, HPLC, Sigma Aldrich, Switzerland) dilution in $40 \mathrm{mM}$ hydrogen chloride solution (Chempur, Piekary Slaskie, Poland) and $2.25 \mathrm{~mL}$ of $20 \mathrm{mM}$ $\mathrm{FeCl}_{3}$ (pure P.A., Chempur, Piekary Slaskie, Poland) in distilled water solution. The mixture was stirred and incubated at $37{ }^{\circ} \mathrm{C}$ for $25 \mathrm{~min}$. Then, the absorbance of the ferrous form with blue colour $\left(\mathrm{Fe}^{2+}-\mathrm{TPTZ}\right.$ complex $)$ was measured at $595 \mathrm{~nm}$, utilizing a UV-spectrophotometer.

In CUPRAC method approximately $0.25 \mathrm{~mL}$ of $\mathrm{CuCl}_{2}(0.01 \mathrm{M}$, Chempur, Piekary Slaskie, Poland) was mixed with $0.25 \mathrm{~mL}$ of an ethanol solution of $7.5 \times 10^{-3} \mathrm{M}$ neocuproine (assay $\geq 98 \%$, Sigma Aldrich, Shanghai, China) and $0.25 \mathrm{~mL}$ of $\mathrm{CH}_{3} \mathrm{COONH}_{4}$ buffer solution (1 M, Chempur, Piekary Slaskie, Poland), in a test tube followed by addition of catechin and poly(catechin) solution. The total volume of samples was increased to $2 \mathrm{~mL}$ with pure water. The absorbance at $450 \mathrm{~nm}$ was measured against distilled water as reagent blank, after 30 min incubation at room temperature.

The ferric (FRAP) and cupric (CUPRAC) ions reducing capacity was calculated according to the formula:

$$
\Delta \mathrm{A}=\mathrm{A}_{\mathrm{AR}}-\mathrm{A}_{0}
$$

where $A_{0}$ - absorbance of the reagent sample, $A_{A R}$ - absorbance after reaction [29].

The FRAP and CUPRAC analysis were made on three control samples and the average results were described in the manuscript. Computations were done for the means and standard deviations of three independent samples $(n=3)$. The measurement uncertainty was given as standard deviation.

\subsection{Antibacterial and Anti-Fungal Tests}

The research was carried out using the dynamic "flask shake methods". The following bacterial test strains were used in the research: Escherichia coli ATCC 8739, Staphylococcus aureus ATCC 6538, Bacillus subtilis ATCC 6633 and fungi: Candida albicans ATCC 10231 and Aspergillus niger ATCC 16404. The cultures were stored on slants with Merck's TSA (bacteria) and MEA (fungi) medium at $6{ }^{\circ} \mathrm{C}$. The strains were activated before the experiment. $10 \mathrm{mg}$ of catechin and poly(catechin) were placed in test tubes, to which were added $9.9 \mathrm{~mL}$ of nutrient broth, and then $0.1 \mathrm{~mL}$ of a suspension of test microorganisms suspended in physiological saline.

The samples were incubated under dynamic conditions, on a shaker $(150 \mathrm{rpm})$ for $24 \mathrm{~h}$ at the temperature of $30^{\circ} \mathrm{C}$ (B. subtilis and A. niger) and $37^{\circ} \mathrm{C}$ (other strains).

The number of microorganisms in the tubes after $24 \mathrm{~h}$ of incubation was determined by the culture method on TSA (bacteria) and MEA (fungi). In addition, the control samples (only microorganisms) were counted at the start of the experiment $(t=0)$. The results are given as the number of colony forming units $/ \mathrm{mL}$ of medium $(\mathrm{cfu} / \mathrm{mL})$. The dieback rates of microorganisms D were determined (3):

$$
\mathrm{D}=\left(\log \text { number of microorganisms } \mathrm{t}_{=0}-\log \text { number of microorganisms } \mathrm{t}=24\right)
$$

The antibacterial and anti-fungal tests were performed on three control samples. Averaged results were included in the manuscript. Calculations were done for the means and standard deviations of three independent samples $(n=3)$. The measurement uncertainty was given as standard deviation. The measurement uncertainty of the samples was given as standard deviation. For dieback rates of microorganisms D, no standard deviation was given because the value of $\mathrm{D}$ is the difference between the log number of microorganisms $t=0$ and the $\log$ number of microorganisms $t=24$.

\section{Results and Discussion}

Glycerol diglycidyl ether (GDE) is an aliphatic epoxy monomer that can be used as a diepoxy crosslinker. Its properties include low shrinkage, good adhesion, and good 
thermo-mechanical properties. GDE can be used in the formation of epoxy materials, which can further be used in biodegradable plastics [30,31].

In Figure 1A, the mechanism of catechin cross-linking with GDE is proposed. The epoxy groups in GDE can readily react with the phenol $\mathrm{OH}$ groups in (+)-catechin, generating polymeric particles. The reaction was accompanied by a color change of the catechin powder from slightly orange to black as shown in the photos in Figure 1B. In addition to the color change, there was also some change in catechin powder morphology relative to poly(catechin).

Based on the SEM images (Figure 1C,D), the morphology of the samples was assessed. The (+)-catechin was characterized by a needle-shaped structure (Figure 1C). As a result of the cross-linking reaction, $(+)$ catechins were linked together by GDE. In the SEM pictures of poly(catechin) (Figure 1D), unlike the needle-shaped monomer, ball-shaped structures covered with fine needles were visible. The morphology of poly(catechin) resembled knots of wool. The ball-shaped structures could correspond to the GDE crosslinker. The needles were particles of catechin, however, and as a result of polymerization, they became fragmented.

The achieved poly(catechin) powder was prepared for liquid NMR analysis, however it was only partially soluble in water, DMF and DMSO, which made liquid NMR analysis impossible. As test results, only signals corresponding to the solvents were obtained (deuterated water $4.8 \mathrm{ppm}$ and DMSO $2.5 \mathrm{ppm} ; 3.3-4.8 \mathrm{ppm}$ ). The ${ }^{1} \mathrm{H}$ NMR spectra of poly(catechin) in deuterated water and DMSO are shown in supplementary materials (Figure S1). Limited solubility may indicate a strong cross-linking of the polymeric flavonoid, and also makes the structure analysis much more difficult.

Particle formation via the epoxy crosslinking reaction of (+) catechin with GDE was confirmed by FTIR spectroscopy as shown in Figure 2A. As can be seen from Figure 2A, the infrared spectrum of poly(catechin) powder differed from the reference (+)-catechin spectrum, which indicated that a compound with a different structure was obtained from the (+)-catechin monomer.

Infrared spectroscopy confirmed the structure of the polymeric catechin. According to the literature data $[26,27]$ on the polymerization with the cross-linking compound of other flavonoids, such as quercetin and rutin, the following bands present in the spectrum of poly (catechins) were characteristic of the polymeric form of flavonoids: $1370-1250 \mathrm{~cm}^{-1}$. aryl stretching vibrations, $3700-3000 \mathrm{~cm}^{-1}$ - wide bands corresponding to the formation of free $\mathrm{OH}$ derived from GDE, $1061 \mathrm{~cm}^{-1}$ - C-CO-C in ketones, and $750-790 \mathrm{~cm}^{-1}$ as well as $800-900 \mathrm{~cm}^{-1}$ - epoxies (from GDE). In addition, the spectrum showed the peaks characteristic of the functional groups present in flavonoids: $2930-2920 \mathrm{~cm}^{-1}-\mathrm{Ar}^{-} \mathrm{CH}_{3}$ (more intense than with catechin) and also $1560-1570 \mathrm{~cm}^{-1}$ and $1450-1500 \mathrm{~cm}^{-1}$ [32]. The appearance of the poly(catechin) bands characteristic for the polymeric forms of flavonoids in the spectrum indicated the cross-linking reaction of $(+)$-catechin and the obtaining of a macromolecular/polymeric compound.

Based on the FTIR spectra, the degree of (+)-catechin to poly(catechin) conversion was determined. The peak between 1450 and $1500 \mathrm{~cm}^{-1}$, corresponding to the aromatic ring vibration, was used for the calculations. The peak at $1455 \mathrm{~cm}^{-1}$ did not change after the polymerization reaction and therefore it can be used as an internal reference $[33,34]$. Moreover, the peak at $1360 \mathrm{~cm}^{-1}$, typical for the aryl stretching vibrations was used to calculate the degree of conversion. The appearance of new aryl bonds was characteristic for polymerization of catechin, as well as for other poly(flavonoids) [26,27]. The height of the peaks was measured in centimetres from the baseline to the maximum point of the absorbance band. The degree of conversion of (+)-catechin to poly(catechin) was calculated according to the Equation (4):

$$
D C(\%)=\left(\frac{\frac{h_{1360}}{h_{1455}} \text { poly }(\text { catechin })}{\frac{h_{1360}}{h_{1455}} \text { catechin }}-1\right) \times 100 \%
$$


where $h_{1360}$ is the height of the band at $1360 \mathrm{~cm}^{-1}$, and $h_{1455}$ is the height of the band at $1455 \mathrm{~cm}^{-1}$.

A

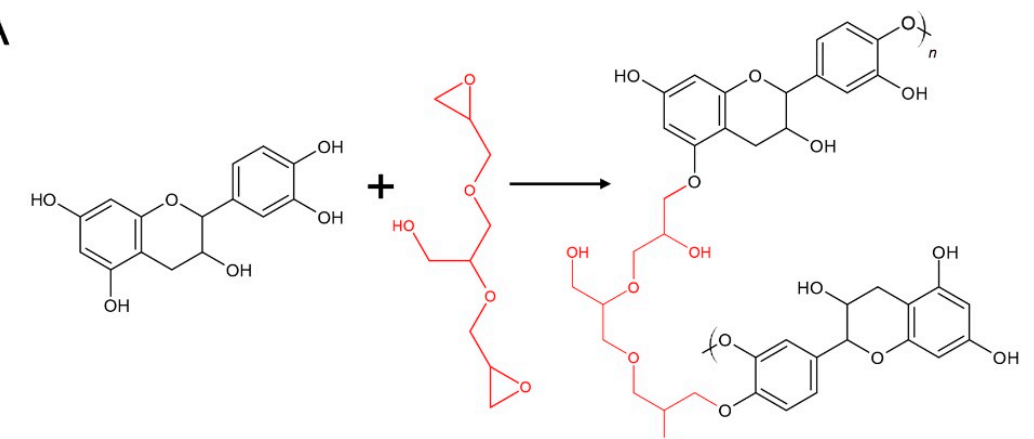

B

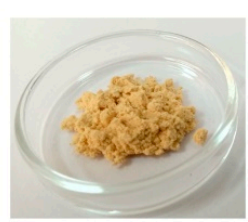

(+)-Catechin

C
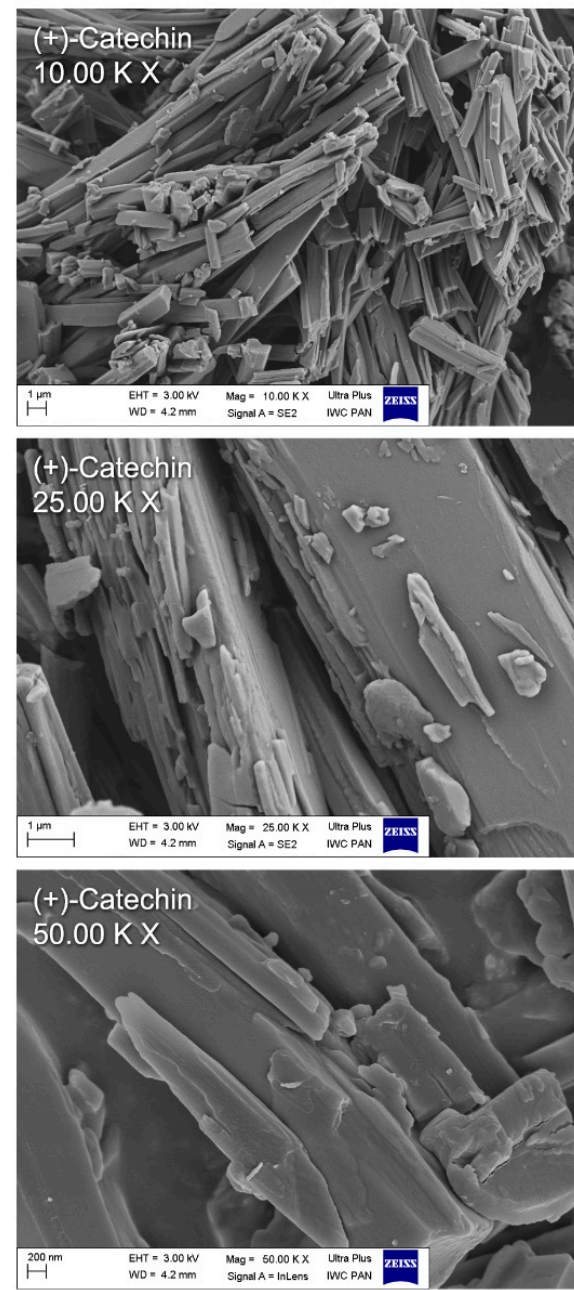

$\mathrm{OH}$

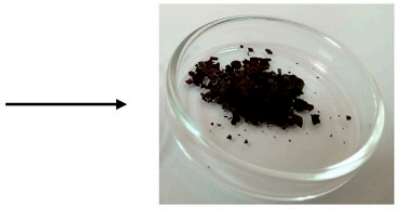

Poly(catechin)

$\mathrm{D}$
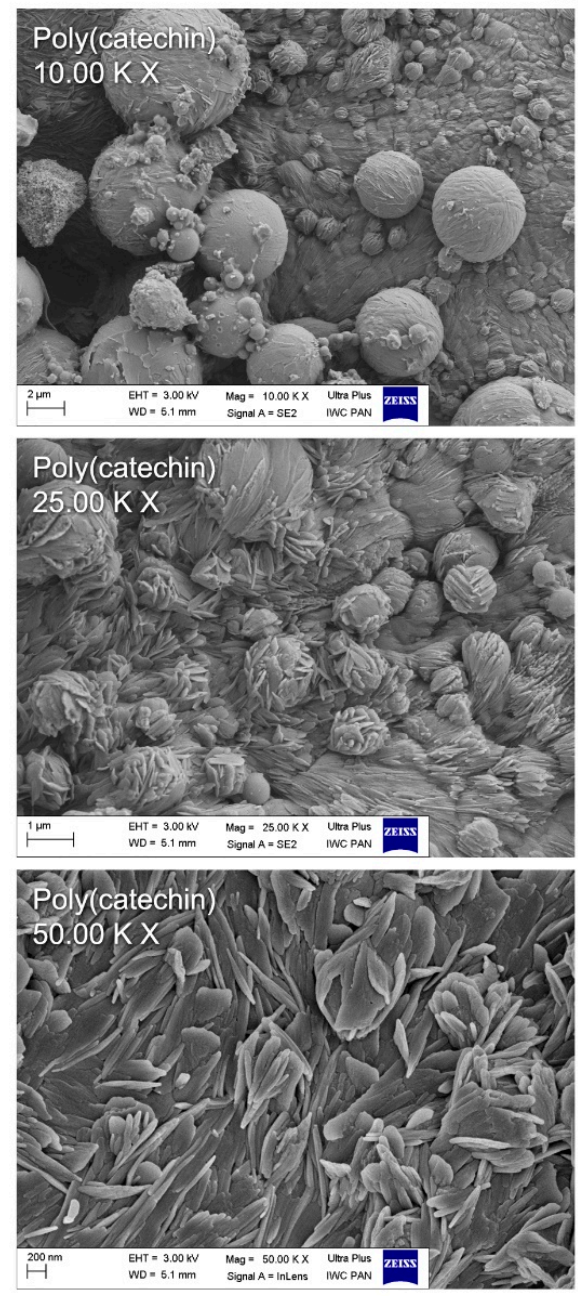

Figure 1. Scheme of the polymerization reaction of (+)-catechin with cross-linking compound (A); visual color change of (+)-catechin during polymerization with GDE (digital camera photos) (B); SEM images at $10.00 \mathrm{KX}, 25.00 \mathrm{KX}$ and $50.00 \mathrm{KX}$ magnification of (+)-catechin (C) and poly(catechin) (D). 

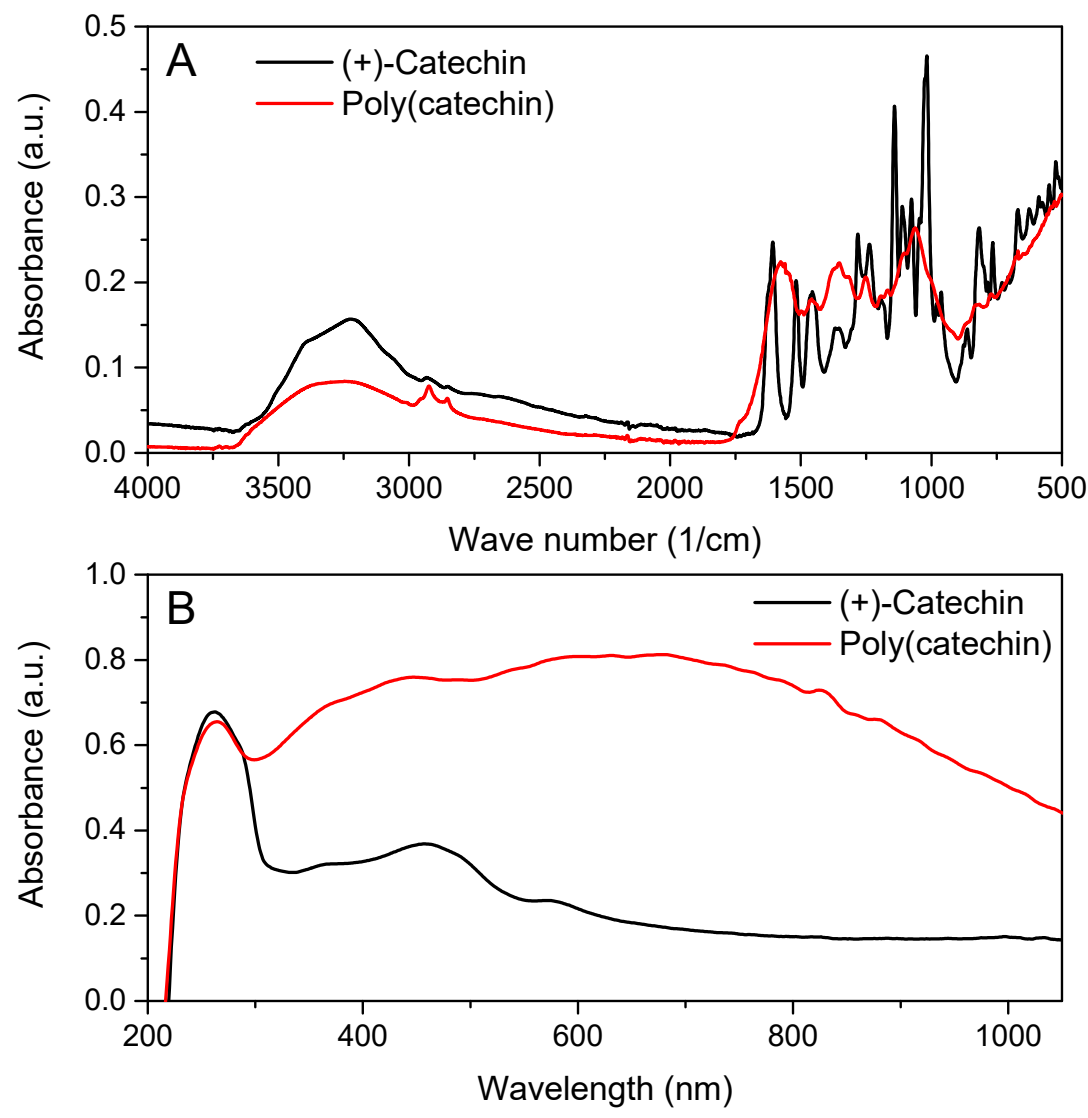

Figure 2. FTIR spectra (A) and UV-Vis spectra (B) of (+)-catechin and poly(catechin) powders.

The degree of conversion of (+)-catechin to poly(catechin) was $90 \%$. The high value of the degree of conversion may indicate a good efficiency of the catechin cross-linking reaction.

The UV-Vis spectroscopy also showed a change in catechin structure after the reaction with GDE. Figure 2B shows the UV-Vis spectra of (+)-catechin and poly(catechin) powders. The (+)-catechin spectrum had two characteristic peaks with maxima at 250 and $460 \mathrm{~nm}$. Poly(catechin) powders were also characterized by two peaks - with a maximum at 250 $\mathrm{nm}$ and a broad peak between 300 and $900 \mathrm{~nm}$. According to the literature, a broad peak between $300 \mathrm{~nm}$ and $550 \mathrm{~nm}$ is specific for oligomeric form of catechins, obtained by enzymatic oligomerization [35]. Additionally, the broad peak between 300 and $750 \mathrm{~nm}$ was typical for the poly(catechin) obtained in the photopolymerization reaction [36].

Poly(catechin) powder was subjected to differential scanning calorimetry DSC. The samples were heated from -80 to $400^{\circ} \mathrm{C}$ at a rate of $10{ }^{\circ} \mathrm{C} / \mathrm{min}$ in an air atmosphere. For comparison, differential scanning calorimetry of the reference (+)-catechin was performed. The results are shown in the thermogram in Figure 3 and in Table 1.

Table 1. DSC analysis of (+)-catechin and poly(catechin).

\begin{tabular}{|c|c|c|c|c|c|}
\hline Sample & $\mathrm{T}_{\mathrm{g}}\left[{ }^{\circ} \mathrm{C}\right]$ & $\Delta \mathbf{H}_{\mathrm{m}}[\mathrm{J} / \mathrm{g}]$ & $\mathrm{T}_{\mathrm{m}}\left[{ }^{\circ} \mathrm{C}\right]$ & $\Delta \mathbf{H}_{\mathrm{o}}[\mathrm{J} / \mathrm{g}]$ & $\mathrm{T}_{\mathbf{0}}\left[{ }^{\circ} \mathrm{C}\right]$ \\
\hline$(+)$-Catechin & a.u. & $\begin{array}{l}49.4 \\
20.5\end{array}$ & $\begin{array}{l}134.3 \\
171.4\end{array}$ & 13.6 & 286.3 (endset) \\
\hline Poly(catechin) & a.u. & 173.5 & 126.5 & 274.6 & 351.8 (endset) \\
\hline
\end{tabular}

$\mathrm{T}_{\mathrm{g}}$ - glass transition temperature, $\Delta \mathrm{H}_{\mathrm{m}}$ - melting enthalpy, $\mathrm{T}_{\mathrm{m}}$ - melting point, $\Delta \mathrm{H}_{\mathrm{o}}$ - oxidation and degradation enthalpy, $\mathrm{T}_{\mathrm{o}}$ - oxidation and degradation temperature. Standard deviations: temperature $\pm 0.8{ }^{\circ} \mathrm{C}$; enthalpy $\pm 1.4 \mathrm{~J} / \mathrm{g}$. 


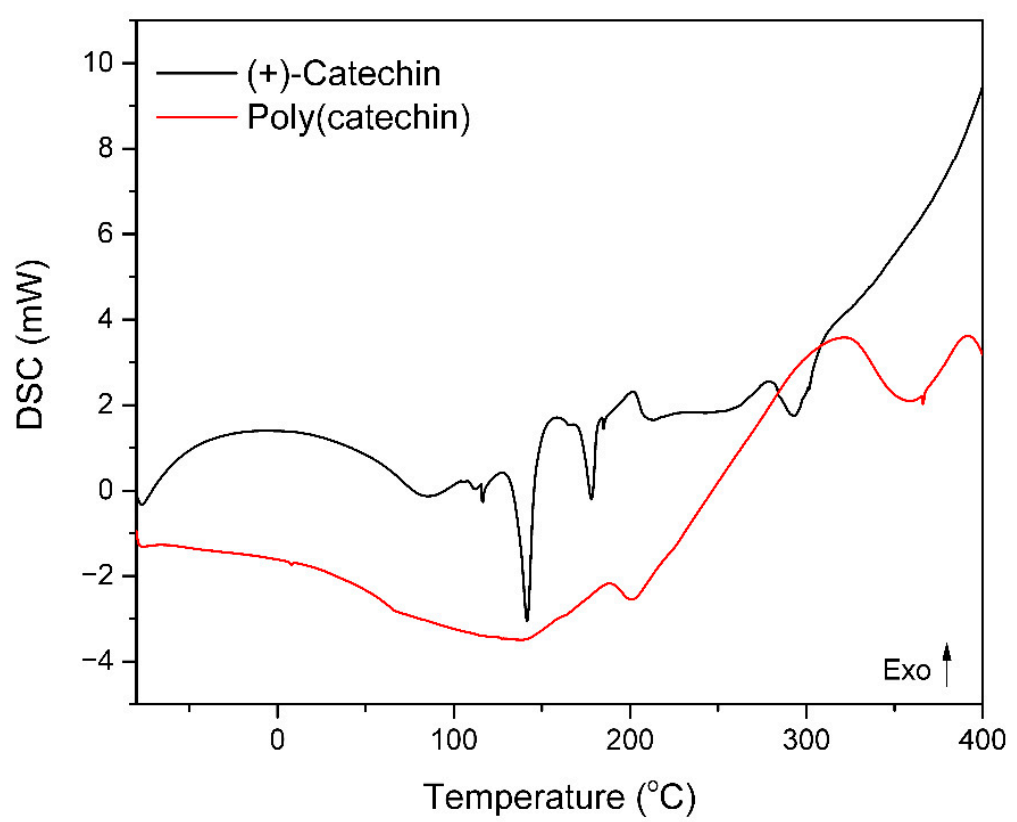

Figure 3. DSC thermograms of (+)-catechin and poly(catechin).

The (+)-catechin thermogram showed two endothermic peaks corresponding to the melting of the sample and exothermic peak related to oxidation and degradation of flavonoid. On the thermogram of poly(catechin) were also found endtothermic peak corresponding to the melting of the material and an exothermic peak of oxidation associated with the decomposition of the poly(catechin). Both tested samples did not have the glass transition temperature $\mathrm{T}_{\mathrm{g}}$.

The poly(catechin) had a lower melting point than the monomeric flavonoid. This may be due to the addition of the GDE cross-linker, which may lower the $T_{m}$. The enthalpy of melting of poly(catechin) $(173.5 \pm 1.4 \mathrm{~J} / \mathrm{g})$ was about 2.5 times higher than that of melting of catechin $(49.4+20.5=69.9 \pm 1.4 \mathrm{~J} / \mathrm{g})$. Moreover, the poly (catechin) had a higher final oxidation temperature $\mathrm{T}_{\mathrm{o}}\left(\right.$ by $65.5^{\circ} \mathrm{C}$ ) and a higher enthalpy of oxidation $\Delta \mathrm{H}_{\mathrm{o}}$ (about 20 times) then (+)-catechin. Thus, the polymeric form of catechin showed greater resistance to oxidation than the monomeric (+)-catechin. Due to the cross-linked structure of poly(catechin), oxidative processes proceed slower than in monomeric flavonoid. In the monomeric structure of the (+)-catechin there may be more unbound functional groups that react with oxygen during oxidation. In poly(catechin) these groups are linked by network nodes and their oxidation may be hindered and limited.

In the next step, the thermal stability of the flavonoid and the poly(flavonoid) was determined using thermogravimetry. The results of the TG analysis are shown in Figure 4 and Table 2.

Table 2. T10, T50, and T55 of (+)-catechin and poly(catechin). Standard deviation: temperature $\pm 0.7^{\circ} \mathrm{C}$.

\begin{tabular}{cccc}
\hline Sample & T10 $\left({ }^{\circ} \mathbf{C}\right)$ & T50 $\left({ }^{\circ} \mathbf{C}\right)$ & T55 $\left({ }^{\circ} \mathbf{C}\right)$ \\
\hline (+)-Catechin & 248 & 613 & 719 \\
Poly(catechin) & 156 & 730 & 800 \\
\hline
\end{tabular}

The decomposition of (+)-catechin was in two stages (Figure 4). The first stage took place at $200{ }^{\circ} \mathrm{C}$ and was accompanied by a weight loss of $4.9 \%$. The second stage of catechin decomposition took place in the temperature range of $282-327 \pm 0.7^{\circ} \mathrm{C}$, for which a weight loss of $52 \%$ was noted. Poly(catechin) also decomposed in two stages. The first stage of decomposition occurred around $200{ }^{\circ} \mathrm{C}$, and the weight loss was $6.7 \%$. The second stage of 
decomposition followed in the temperature range of $230-360 \pm 0.7^{\circ} \mathrm{C}$. The second stage was accompanied by a sample weight loss of only $22.3 \%$.

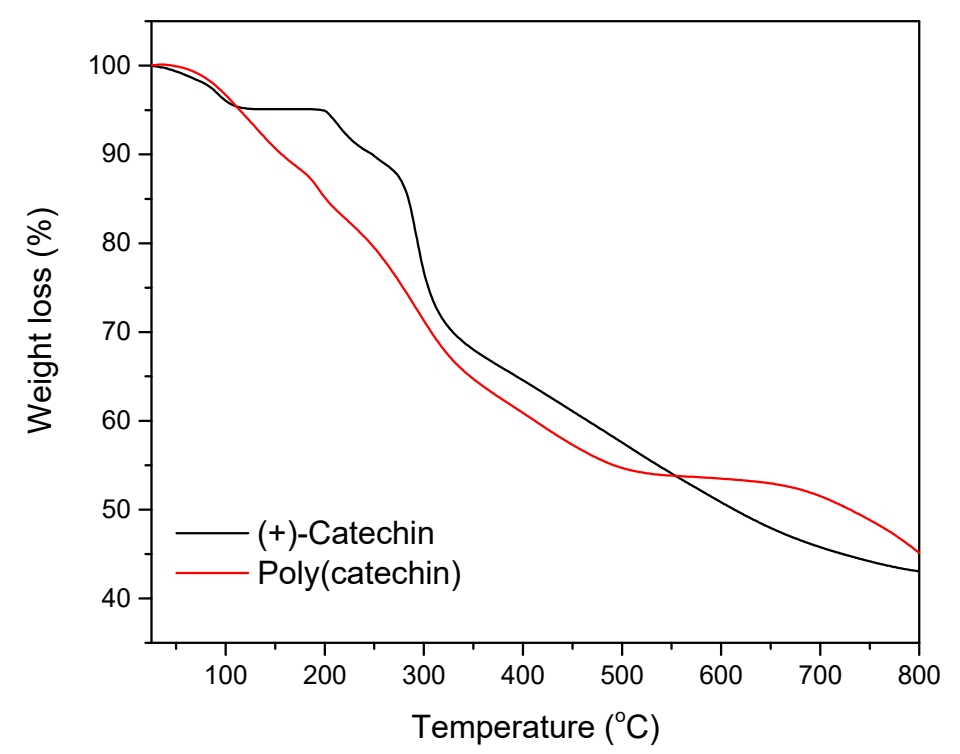

Figure 4. Thermal decomposition (TG) curves of (+)-catechin and poly(catechin).

Table 2 shows the values of T10, T50, and T55 for the samples analyzed, where T10, T50, and T55 refer to the loss of $10 \%, 50 \%$, and $50 \%$, respectively, of the initial mass of the material as a function of temperature. The T10, T50 and T55 were determined because further weight loss of the samples was not visible at the measurement conditions (25-800 $\left.{ }^{\circ} \mathrm{C}\right)$. The degradation of poly(catechin) started at a lower temperature than that of catechin $\left(\mathrm{T} 10\right.$ poly $($ catechin $)=156 \pm 0.7^{\circ} \mathrm{C}, \mathrm{T} 10(+)$-catechin $\left.=248 \pm 0.7^{\circ} \mathrm{C}\right)$. This may have been due to the addition of the GDE cross-linker, which could lower the T10 value. The temperature of the half-decomposition of poly(catechin) T50 was by $117 \pm 0.7^{\circ} \mathrm{C}$ higher than that of the monomeric (+)-catechin, which indicated higher thermal stability of the polymeric form of $(+)$-catechin.

The temperature of half-decomposition of poly(catechin), higher by $117 \pm 0.7{ }^{\circ} \mathrm{C}$, and about two times lower weight loss of poly(catechin) during the second stage of decomposition of the compound, testified to higher thermal stability of the polymeric form of (+)-catechin. The cross-linked structure of poly(catechin) can limit heat ingress into the molecules and improves thermal stability. Moreover, in the polymeric $(+)$-catechin there may be fewer unbound functional groups that are less thermally resistant than those linked by nodes.

In accordance with the literature data [37], the complex aromatic structure of natural condensed catechins - tannins lead to high thermal resistance. It has been described that the decomposition of Acacia dealbata tannin was almost complete at a temperature of $600{ }^{\circ} \mathrm{C}$, the remaining weight of tannin was approximately $44 \%$, so the weight loss of the sample was $56 \%$. The weight loss of poly(catechin) at $600{ }^{\circ} \mathrm{C}$ was about $47 \%$ and of the reference catechin was about $49 \%$. Comparing the obtained results with the literature on the condensed tannin, it should be stated that both (+)-catechin and poly(catechin) at $600{ }^{\circ} \mathrm{C}$ had lower thermal stability than natural tannin.

Figure 5 shows the activities of (+)-catechin and poly(catechin) for the reduction of free radicals ABTS and DPPH and for the reduction of transition metal ions - iron (FRAP) and copper (CUPRAC). (+)-Catechin and poly(catechin) solutions at a concentration of $0.1 \mathrm{mg} / \mathrm{mL}$ in distilled water were prepared for the analyzes. Catechin was highly soluble and poly(catechin) only partially. The limited solubility of the polymeric (+)-catechin could have influenced the research results. In addition, poly(catechin) solutions were character- 
ized by an intense, dark color, which could also affect the results of spectrophotometric colorimetric methods.
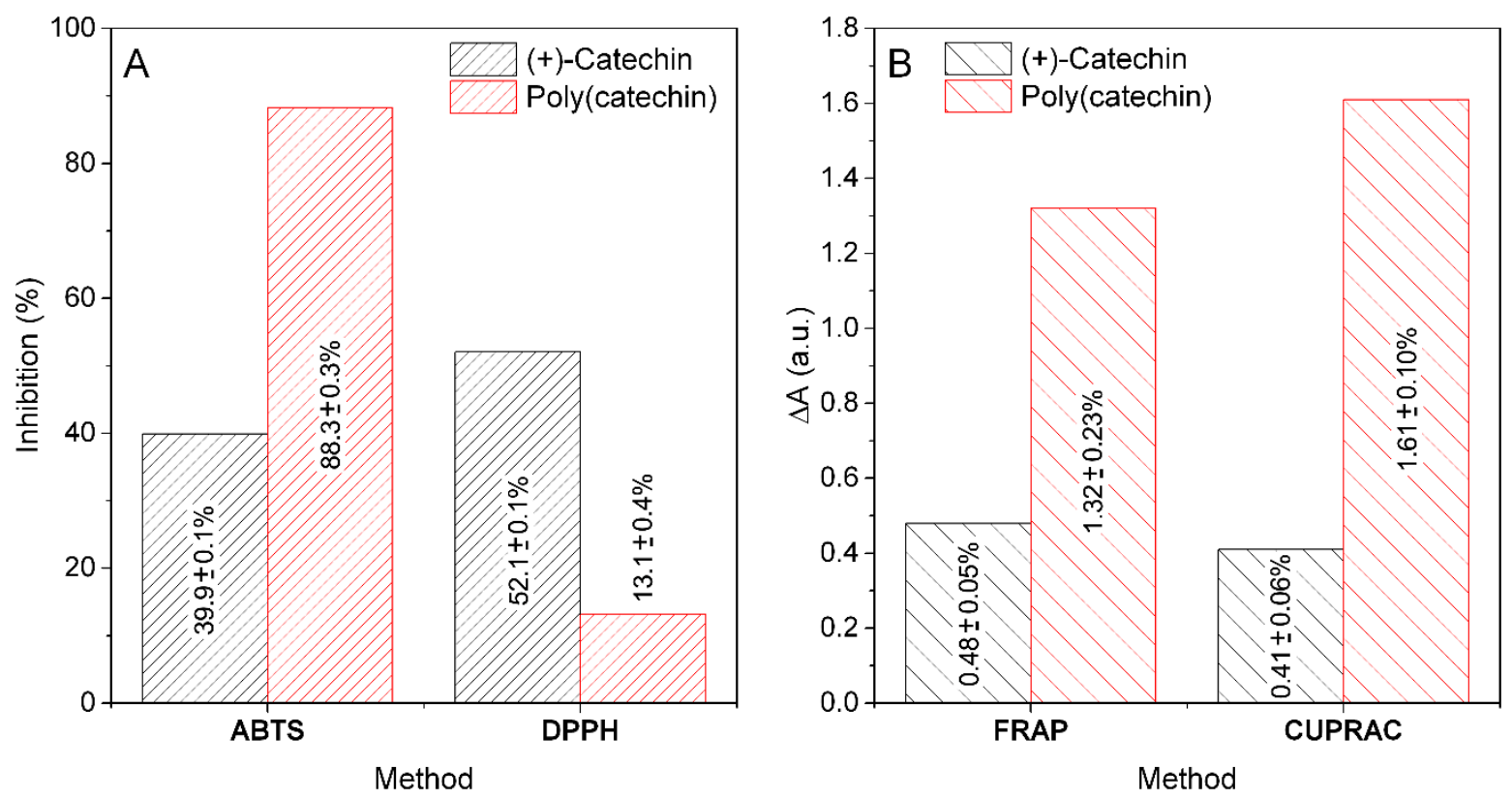

Figure 5. Ability of $0.1 \mathrm{mg} / \mathrm{mL}$ (+)-catechin and poly(catechin) to reduce free radicals ABTS and DPPH (A) and for reduce of iron and cupric ions measured by FRAP and CUPRAC methods (B).

The applied ABTS and DPPH methods are based on the reactions of quenching synthetic free radicals. In such methods, the colored active radical is reduced by the antioxidant present in the test sample to a colorless product. The ABTS method enables the determination of hydrophobic and hydrophilic antioxidants. The analogous DPPH method is very sensitive and serves only for the analysis of hydrophobic compounds. The polymeric form of $(+)$-catechin showed a very high antioxidant activity towards the reduction of ABTS radicals $(88.3 \pm 0.3 \%$; TEAC $662.3 \pm 3.1 \mathrm{mmolT} / 100 \mathrm{~g})$. The activity for reducing ABTS radicals by poly(catechin) was much greater (around 2.2 times) than that of the monomeric form $(39.9 \pm 0.1 \%$; TEAC $331.8 \pm 1.2 \mathrm{mmolT} / 100 \mathrm{~g})$. In contrast to the ABTS method, in the DPPH method, poly(catechin) was characterized by lower antiradical activity (about 3.9 times; $13.0 \pm 0.4 \%$; TEAC $477.6 \pm 2.5 \mathrm{mmolT} / 100 \mathrm{~g}$ ) than (+)-catechin (52.1 $\pm 0.1 \%$; TEAC $492.6 \pm 1.9 \mathrm{mmolT} / 100 \mathrm{~g})$. The results of ABTS and DPPH tests may indicate a better affinity of poly(catechin) to the ABTS method intended for the determination of hydrophilic and hydrophobic compounds, in contrast to the DPPH method - intended for the analysis of only hydrophobic compounds. Sahiner showed similar results in the determination of DPPH for rutin and poly(rutin) [27]. The scavenging capacity of DPPH free radicals by poly(rutin) particles is lower compared to rutin monomer and $\alpha$-tocopherol. The poly(rutin) particles still have phenolic groups on their surfaces and have the ability to annihilate DPPH radicals. According to author, this difference could be attributed to the bigger size of particles of poly(rutin) and the lesser number of $\mathrm{OH}$ functional groups in comparison to rutin. Active groups that scavenged DPPH free radicals could be linked by network nodes during polymerization, as a result of which their number decreased, and thus the ability to scavenge DPPH radicals decreased.

The second group of spectrophotometric methods that were used to analyze (+)catechin and poly(catechin) were methods based on the reduction of multivalent metal ions. The poly(catechin) obtained as a result of the reaction with the cross-linker was characterized by a better ability to reduce iron ions (FRAP assay, about 2.7 times) and copper (CUPRAC test, around 3.9 times). The polymerization of (+)-catechin had a positive effect on the improvement of these properties. Polyvalent metal ions can catalyze the aging 
processes, therefore the ability to reduce and chelate such ions is a very important property for potentially stabilizers.

Samples of (+)-catechin and poly(catechin) were tested for antibacterial and antifungal activity. The test results are summarized in Table 3.

Table 3. Antibacterial and antifungal activity of (+)-catechin and poly(catechin).

\begin{tabular}{|c|c|c|c|c|c|}
\hline \multirow[t]{2}{*}{ Sample } & \multicolumn{2}{|c|}{$\begin{array}{l}\text { The Number of Microorganisms } \\
{\left[\mathrm{cfu} / \mathrm{cm}^{2}\right]}\end{array}$} & \multicolumn{2}{|c|}{$\begin{array}{l}\text { Log of the Number of } \\
\text { Microorganisms }\end{array}$} & \multirow[t]{2}{*}{ D } \\
\hline & $t=0$ & $t=24$ & $t=0$ & $t=24$ & \\
\hline \multicolumn{6}{|c|}{ Escherichia coli } \\
\hline $\begin{array}{l}\text { Control medium } \\
(+)-C a t e c h i n \\
\text { Poly(catechin) }\end{array}$ & $1.67 \pm 0.21 \times 10^{6}$ & $\begin{array}{l}9.57 \pm 1.56 \times 10^{7} \\
1.63 \pm 0.25 \times 10^{7} \\
1.90 \pm 0.29 \times 10^{7}\end{array}$ & $6.23 \pm 0.05$ & $\begin{array}{l}7.98 \pm 0.07 \\
7.20 \pm 0.07 \\
7.28 \pm 0.05\end{array}$ & $\begin{array}{l}1.75 \\
0.97 \\
1.05\end{array}$ \\
\hline $\begin{array}{l}\text { Control medium } \\
(+)-C a t e c h i n \\
\text { Poly(catechin) }\end{array}$ & $6.53 \pm 0.25 \times 10^{5}$ & $\begin{array}{c}\text { Staphylococcus aureus } \\
1.13 \pm 0.13 \times 10^{8} \\
1.63 \pm 0.08 \times 10^{7} \\
1.33 \pm 0.30 \times 10^{6}\end{array}$ & $5.81 \pm 0.03$ & $\begin{array}{l}8.04 \pm 0.10 \\
7.20 \pm 0.06 \\
6.11 \pm 0.10\end{array}$ & $\begin{array}{l}2.23 \\
1.39 \\
0.30\end{array}$ \\
\hline $\begin{array}{l}\text { Control medium } \\
(+)-C a t e c h i n \\
\text { Poly(catechin) }\end{array}$ & $1.33 \pm 0.25 \times 10^{6}$ & $\begin{array}{l}\text { Bacillus subtilis } \\
1.63 \pm 0.21 \times 10^{7} \\
1.83 \pm 0.21 \times 10^{7} \\
9.60 \pm 0.40 \times 10^{6}\end{array}$ & $6.11 \pm 0.08$ & $\begin{array}{l}7.20 \pm 0.06 \\
7.26 \pm 0.05 \\
6.98 \pm 0.02\end{array}$ & $\begin{array}{l}1.09 \\
1.14 \\
0.87\end{array}$ \\
\hline $\begin{array}{l}\text { Control medium } \\
(+)-C a t e c h i n \\
\text { Poly(catechin) }\end{array}$ & $1.87 \pm 0.38 \times 10^{5}$ & $\begin{array}{l}\text { Candida albicans } \\
3.74 \pm 1.47 \times 10^{6} \\
1.83 \pm 0.21 \times 10^{6} \\
1.50 \pm 0.20 \times 10^{6}\end{array}$ & $5.28 \pm 0.08$ & $\begin{array}{l}6.57 \pm 0.18 \\
6.26 \pm 0.05 \\
6.18 \pm 0.06\end{array}$ & $\begin{array}{l}1.29 \\
0.98 \\
0.90\end{array}$ \\
\hline $\begin{array}{l}\text { Control medium } \\
(+)-\text { Catechin } \\
\text { Poly(catechin) }\end{array}$ & $1.33 \pm 0.40 \times 10^{4}$ & $\begin{array}{l}\text { Aspergillus niger } \\
2.37 \pm 0.42 \times 10^{5} \\
4.17 \pm 0.55 \times 10^{2} \\
6.53 \pm 0.31 \times 10^{2}\end{array}$ & $4.11 \pm 0.14$ & $\begin{array}{l}5.38 \pm 0.08 \\
2.62 \pm 0.06 \\
2.81 \pm 0.02\end{array}$ & $\begin{array}{r}1.27 \\
-1.49 \\
-1.30\end{array}$ \\
\hline
\end{tabular}

After $24 \mathrm{~h}$ of incubation, an increase in the number of all organisms was observed in the control medium without polyphenols. An increase in the number of Escherichia coli bacterial cells by about 1 to 1.8 logarithm was recorded in cultures with all materials, which meant that the samples did not show any antibacterial activity against this organism. The increase in the number of Staphylococcus aureus bacterial cells in the culture for poly(catechin) did not exceed 0.5 logarithm, which means that the poly(catechin) sample showed bacteriostatic activity against this organism. The reference (+)-catechin showed no such activity. The increase in the number of Bacillus subtilis bacterial cells was recorded in cultures with all materials at similar levels, which means that the samples showed no antibacterial activity against this bacterial cell.

The increase in the number of Candida albicans yeast cells was recorded in the cultures with all samples. (+)-Catechin and poly(catechin) showed no antimicrobial activity against this organism. The number of Aspergillus niger mold cells after $24 \mathrm{~h}$ increased by more than one row in the polyphenol-free control only. In the remaining samples, containing (+)-catechin and poly(catechin), a decrease in the number of cells was noted in the cultures with both compounds, which meant that they showed antifungal activity. (+)-Catechin and poly (catechin) showed comparable antifungal activity against Aspergillus niger.

In conclusion, the polymeric form of $(+)$-catechin showed antimicrobial activity against Staphylococcus aureus cells. Such activity was not found for the (+)-catechin monomer. Similar results were observed by Sahiner for poly(quercetin) obtained in the reaction with GDE [26]. The author found that poly(quercetin) had a stronger antibacterial effect than quercetin (concentration $0.01 \mathrm{~g} / \mathrm{mL}$ ) on the tested E. coli ATCC 8739, S. aureus ATCC 25323, and B. subtilis ATCC 6633 strains.

In the case of antifungal activity, both (+)-catechin and poly(catechin) were active against Aspergillus niger mold cells. Polyphenols do not completely inhibit the growth of microorganisms, but they prolong the adaptation phase, which was clearly visible in the 
case of organisms that grow longer, such as molds. The obtained results and the lack of antimicrobial activity may also result from the low solubility of the preparations in water and thus the difficult penetration into the cells.

\section{Conclusions}

As a result of the cross-linking reaction with GDE, the polymeric form of $(+)$-catechin was obtained. The limited solubility of poly(catechin) powder made it difficult to determine the structure of the compound. However, FTIR analysis indicated the presence of polymeric bonds characteristic of poly (flavonoids). Moreover, the UV-Vis spectra also had peaks corresponding to the polymeric forms of poly(catechins). The polymeric form of $(+)-$ catechin was characterized by greater resistance to oxidation than the monomer (DSC analysis). Moreover, on the basis of the determination of TG it was found that poly(catechin) has a higher thermal stability than (+)-catechin, however, this stability at $600{ }^{\circ} \mathrm{C}$ is not as high as that of natural condensed tannin. Analysis of the antioxidant activity showed that the polymeric (+)-catechin had better activity for reducing ABTS free radicals and worse for reducing DPPH. Moreover, polymerization of $(+)$-catechin increased the ability to reduce polyvalent metal ions. Poly(catechin) showed antibacterial activity against Staphylococcus aureus, stronger than (+)-catechin, as well as antifungal activity against Aspergillus niger, comparable to the activity of the monomer. Thanks to good resistance to oxidation, high thermal stability, and great ability to reduce metal ions, poly(catechin) can potentially be stabilizers, e.g., for polymeric materials and environmentally friendly materials. Additionally, due to its antimicrobial properties, poly(catechin) can be proposed as a natural functional additive, e.g., for polymeric active packaging.

Supplementary Materials: The following are available online at https:/ / www.mdpi.com/2218-273 X/11/1/50/s1, Figure S1: ${ }^{1} \mathrm{H}$ NMR spectra of poly(catechin) in deuterated water and in DMSO.

Author Contributions: Conceptualization, M.L.-B. and A.M.; methodology, M.L.-B., M.P., and A.M.; software, M.L.-B.; validation, M.L.-B., M.P., and A.M.; formal analysis, A.M.; investigation, M.L.B.; resources, M.L.-B.; data curation, A.M.; writing—original draft preparation, M.L.-B. and M.P.; writing-review and editing, A.M.; visualization, M.L.-B.; supervision, A.M.; project administration, M.L.-B.; funding acquisition, M.L.-B. All authors have read and agreed to the published version of the manuscript.

Funding: This research was funded by the National Science Center, Poland (NCN), grant number 2018/31/N/ST8/02565.

Institutional Review Board Statement: Not applicable.

Informed Consent Statement: Not applicable.

Data Availability Statement: Not applicable.

Conflicts of Interest: The authors declare no conflict of interest.

\section{References}

1. Cosarca, S.; Tanase, C.; Muntean, D.L. Therapeutic Aspects of Catechin and Its Derivatives-An Update. Acta Med. Marisiensis 2019, 2, 21-29.

2. Li, F.; Jin, H.; Xiao, J.; Yin, X.; Liu, X.; Li, D.; Huang, Q. The simultaneous loading of catechin and quercetin on chitosan-based nanoparticles as effective antioxidant and antibacterial agent. Food Res. Int. 2018, 111, 351-360. [CrossRef] [PubMed]

3. Caro, A.A.; Davis, A.; Fobare, S.; Horan, N.; Ryan, C.; Schwab, C. Antioxidant and pro-oxidant mechanisms of (+) catechin in microsomal CYP2E1-dependent oxidative stress. Toxicol. In Vitro 2019, 54, 1-9. [CrossRef] [PubMed]

4. Chunmei, D.; Jiabo, W.; Weijun, K.; Cheng, P.; Xioache, X. Investigation of antimicrobial activity of catechin on Escherichia coli growth by microcalorimetry. Environ. Toxicol. Pharmacol. 2010, 30, 284-288. [CrossRef]

5. Grzesik, M.; Naparlo, K.; Bartosz, G.; Sadowska-Bartosz, I. Antioxidant properties of catechins: Comparison with other antioxidants. Food Chem. 2018, 241, 480-492. [CrossRef]

6. Dobashi, Y.; Hirano, T.; Hirano, M.; Ohkatsu, Y. Antioxidant and photo-antioxidant abilities of catechins. J. Photochem. Photobiol. A 2008, 197, 141-148. [CrossRef]

7. Heim, K.E.; Tagliaferro, A.R.; Bobilya, D.J. Flavonoid antioxidants: Chemistry, metabolism and structure-activity relationships. J. Nutr. Biochem. 2002, 13, 572-584. [CrossRef] 
8. Wu, T.; Zang, X.; He, M.; Pan, S.; Xu, X. Structure Activity Relationship of Flavonoids on Their Anti-Escherichia coli Activity and Inhibition of DNA Gyrase. J. Agric. Food. Chem. 2013, 61, 8185-8190. [CrossRef]

9. Amic, D.; Davidovic-Amic, D.; Beslo, D.; Trinajstic, N. Structure-Radical Scavenging Activity Relationships of Flavonoids. Croat. Chem. Acta 2003, 76, 55-61.

10. Wang, T.-Y.; Li, Q.; Bi, K.-S. Bioactive flavonoids in medicinal plants: Structure, activity and biological fate. Asian J. Pharm. 2018, 13, 12-23. [CrossRef]

11. Chebil, L.; Rhouma, G.B.; Chekir-Ghedira, L.; Ghoul, M. Enzymatic Polymerization of Rutin and Esculin and Evaluation of the Antioxidant Capacity of Polyrutin and Polyesculin. In Biotechnology; IntechOpen: London, UK, 2015; pp. 117-133.

12. Quideau, S.; Deffieux, D.; Douat-Casassus, C.; Pouységu, L. Angew. Plant Polyphenols: Chemical Properties, Biological Activities, and Synthesis. Angew. Chem. 2011, 50, 586-621. [CrossRef] [PubMed]

13. Desentis-Mendoza, R.M.; Hernandez-Sanchez, H.; Moreno, A.; Emilio Rojas del, C.; Chel-Guerrero, L.; Tamariz, J.; Jaramillo-Flores, M.E. Enzymatic Polymerization of Phenolic Compounds Using Laccase and Tyrosinase from Ustilago maydis. Biomacromolecules 2006, 7, 1845-1854. [CrossRef]

14. Bruno, F.F.; Trotta, A.; Fossey, S.; Nagarajan, S.; Nagarajan, R.; Samuelson, L.A.; Kumar, J. Enzymatic Synthesis and Characterization of PolyQuercetin. J. Macromol. Sci. 2010, 47, 1191-1196. [CrossRef]

15. Anthoni, J.; Lionneton, F.; Wieruszeski, J.M.; Magdalou, J.; Engasser, J.M.; Chebil, L.; Humeau, C.; Ghoul, M. Investigation of enzymatic oligomerization of rutin. Rasayan, J. Chem. 2008, 1, 718-731.

16. Castillo, J.; Benavente-Garcia, O.; Lorente, J.; Alcaraz, M.; Redondo, A.; Ortuno, A.; Del Rio, J.A. Antioxidant activity and radioprotective effects against chromosomal damage induced in vivo by X-rays of flavan-3-ols (procyanidins) from grape seeds (Vitisvinifera): Comparative study versus other phenolic and organic compounds. J. Agric. Food Chem. 2000, 48, 1738-1745. [CrossRef] [PubMed]

17. Spencer, J.P.E.; Chaudry, F.; Pannala, A.S.; Srai, S.K.; Debnam, E.; Rice-Evans, C. Decomposition of cocoa procyanidins in the gastric milieu. Biochem. Biophys. Res. Commun. 2000, 272, 236-241. [CrossRef] [PubMed]

18. Kurisawa, M.; Chung, J.E.; Uyama, H.; Kobayashi, S. Laccase-catalyzed Synthesis and Antioxidant Property of Poly(catechin). Macromol. Biosci. 2003, 33, 758-764. [CrossRef]

19. Kurisawa, M.; Chung, J.E.; Kim, Y.J.; Uyama, H.; Kobayashi, S. Amplification of Antioxidant Activity and Xanthine Oxidase Inhibition of Catechin by Enzymatic Polymerization. Biomacromolecules 2003, 4, 469-471. [CrossRef]

20. Hosny, H.; Rosazza, J.P.N. Novel Oxidations of (+)-Catechin by Horseradish Peroxidase and Laccase. J. Agric. Food Chem. 2002, 50, 5539-5545. [CrossRef]

21. Liang, J.-Y.; Wu, J.-Y.; Yang, M.-Y.; Hu, A.; Chen, L.-Y. Photo-catalytic polymerization of catechin molecules in alkaline aqueous. J. Photochem Photobiol, B. 2016, 165, 115-120. [CrossRef]

22. Oliver, S.; Hook, J.M.; Boyer, C. Versatile oligomers and polymers from flavonoids—a new approach to synthesis. Polym. Chem. 2017, 8, 2317-2326. [CrossRef]

23. Chung, J.E.; Kurisawa, M.; Kim, Y.-J.; Uyama, H.; Kobayashi, S. Amplification of Antioxidant Activity of Catechin by Polycondensation with Acetaldehyde. Biomacromolecules 2004, 5, 113-118. [CrossRef] [PubMed]

24. Kim, Y.-J.; Chung, J.E.; Kurisawa, M.; Uyama, H.; Kobayashi, S. Regioselective Synthesis and Structures of (+)-Catechin-Aldehyde Polycondensates. Macromol. Chem. Phys. 2003, 204, 1863-1868. [CrossRef]

25. Kim, Y.-J.; Uyama, H.; Kobayashi, S. Inhibition effects of (+)-catechin-aldehyde polycondensates on proteinases causing proteolytic degradation of extracellular matrix. Biochem Biophys Res. Commun. 2004, 320, 256-261. [CrossRef] [PubMed]

26. Sahiner, N. One step poly(quercetin) particle preparation as biocolloidand its characterization. Colloids Surf. A Physicochem. Eng. Asp. 2014, 452, 173-180. [CrossRef]

27. Sahiner, N. One step poly(rutin) particle preparation as biocolloid and its characterization. Mater. Sci. Eng. C 2014, 44, 9-16. [CrossRef] [PubMed]

28. Masek, A.; Chrzescijanska, E.; Latos, M.; Zaborski, M.; Podsedek, A. Antioxidant and Antiradical Properties of Green Tea Extract Compounds. Int. J. Electrochem. Sci. 2017, 12, 6600-6610. [CrossRef]

29. Masek, A.; Chrzescijanska, E.; Latos, M.; Kosmalska, A. Electrochemical and Spectrophotometric Characterization of the Propolis Antioxidants Properties. Int. J. Electrochem. Sci. 2019, 14, 1231-1247. [CrossRef]

30. Kasetaite, S.; Ostrauskaite, J.; Grazuleviciene, V.; Svediene, J.; Bridziuvien, D. Photocross-linking of glycerol diglycidyl ether with reactive diluents. Polymer Bull. 2015, 72, 3191-3208. [CrossRef]

31. Kasetaite, S.; Ostrauskaite, J.; Grazuleviciene, V.; Bridziuviene, D.; Budreckiene, R.; Rainosalo, E. Biodegradable photocross-linked polymers of glycerol diglycidyl ether and structurally different alcohols. React. Funct. Polym. 2018, 122, 42-50. [CrossRef]

32. Heneczkowski, M.; Kopacz, M.; Nowak, D.; Kuźniar, A. Infrared spectrum analysis of some flavonoids. Acta Pol. Pharm. 2001, 6, 415-420.

33. Herrera-González, A.M.; Caldera-Villalobos, M.; Pérez-Mondragón, A.A.; Cuevas-Suárez, C.E.; González-López, J.A. Analysis of Double Bond Conversion of Photopolymerizable Monomers by FTIR-ATR Spectroscopy. J. Chem. Educ. 2019, 96, 1786-1789. [CrossRef]

34. Collares, F.M.; Portella, F.F.; Leitune, V.C.B.; Samuel, S.M.W. Discrepancies in Degree of Conversion Measurements by FTIR. Braz. Oral Res. 2014, 28, 1-7. 
35. Nagarajan, S.; Nagarajan, R.; Braunhut, S.J.; Bruno, F.; McIntosh, D.; Samuelson, L.; Kumar, J. Biocatalytically Oligomerized Epicatechin with Potent and Specific Anti-proliferative Activity for Human Breast Cancer Cells. Molecules. 2008, 13, $2704-2716$. [CrossRef] [PubMed]

36. Latos-Brozio, M.; Masek, A. Natural polymeric compound based on high thermal stability catechin from green tea. Biomolecules 2020, 10, 1191. [CrossRef] [PubMed]

37. Lisperguer, J.; Saravia, Y.; Vergara, E. Structure and thermal behavior of tannins from Acacia dealbata bark and their reactivity toward formaldehyde. J. Chil. Chem. Soc. 2016, 61, 3188-3190. [CrossRef] 